\title{
Borohydride electro-oxidation by Ag-doped lanthanum chromites
}

\author{
S SURESH BALAJI, A USHA and V V GIRIDHAR* \\ Nano-Scale Electrocatalysis and Sensor Research Group, Electrodics and Electrocatalysis Division, \\ CSIR-Central Electrochemical Research Institute, Karaikudi 630 006, India \\ e-mail: giridharv@cecri.res.in
}

MS received 18 July 2013; revised 8 November 2013; accepted 16 November 2013

\begin{abstract}
The electrocatalytic activity of Ag-doped lanthanum chromites electrode materials viz., $\mathrm{LaCr}_{0.4} \mathrm{Ag}_{0.6} \mathrm{O}_{3}$ and $\mathrm{LaCr}_{0.7} \mathrm{Ag}_{0.3} \mathrm{O}_{3}$ prepared by decomposing the precursor complex is studied. Pure $\mathrm{LaCrO}_{3}$ is synthesized by combustion route using oxalic acid as a fuel. The decomposition behaviour of the assynthesized powder obtained in the latter method is characterized by TGA-DTA and XRD. Both the precursor complex and the as-synthesized powder are calcined at $900^{\circ} \mathrm{C}$ for 7 and $10 \mathrm{~h}$, respectively. XRD of the final product after calcinations indicated the formation of perovskite phase with minor amounts of impurity phases of component oxides in the Ag-doped lanthanum chromites and pure perovskite phase in the undoped one. The surface morphology of the perovskites is studied by SEM. The electrocatalytic activity of the perovskite powders for borohydride oxidation is studied by using cyclic voltammetry (CV) at a catalyst loading of $0.7 \mathrm{mgcm}^{-2}$ for both Ag-doped and undoped $\mathrm{LaCrO}_{3}$ coated on glassy carbon substrate. Calibration plots are obtained by plotting the anodic peak current versus concentration of borohydride in the range of $20-100 \mathrm{mM}$. The sensitivities of the three perovskites towards borohydride oxidation indicated that $\mathrm{LaCr}_{0.4} \mathrm{Ag}_{0.6} \mathrm{O}_{3}$ is the best among all the perovskites studied giving a value of $1.395 \mu \mathrm{A} / \mathrm{mM}$.
\end{abstract}

Keywords. Ag-doped lanthanum chromites; borohydride oxidation; perovskite; precursor complex; combustion route.

\section{Introduction}

Perovskite-type oxides, general formula $\mathrm{ABO}_{3}(\mathrm{~A}$ alkali, alkaline earth or lanthanide group metal(s) and B - transition metal(s)), play an important role in the preparation of catalysts for specific applications. The ideal perovskite structure is cubic in which 12 and 6 oxygen atoms surround the larger A-site cation and smaller B-site cations, respectively. Perovskite materials have several technological applications including in their use as high-temperature furnace electrodes, ${ }^{1}$ as electrode material in intermediate temperature solid oxide fuel cells (IT-SOFC), ${ }^{2}$ as electrolytes in protonconducting solid oxide fuel cells (PC-SOFC), ${ }^{3}$ as catalysts for the treatment of automobile exhaust ${ }^{4}$ and as sensors. ${ }^{5}$ They offer a wide range of phenomena to be studied such as ferroelectricity, superconductivity, high temperature ionic conductivity, a variety of magnetic ordering, ${ }^{6}$ etc. and also provide excellent proton transport properties in addition to being stable and active in a strongly acidic environment. A wide range of electronic and surface properties can be tailor-made by suitable

*For correspondence choice of A and B sites. These properties make them useful for variety of redox reactions especially in solid oxide fuel cell energy sources.

Many preparative methods exist in literature for the synthesis of perovskites e.g., co-melting, solgel, hydrothermal, microwave heating, decomposition of precursor complexes based on citrate, ethylenediamminetetraacetate (EDTA), diethylenetriaminepentaacetate (DTPA) and nitrilotriacetic acid ligands and combustion routes, etc. Since powdered catalysts have more surface area/volume ratio and have more active sites for any chemical/electrochemical reaction to take place, it is preferable to study synthesis methods that give rise to the formation of powdered perovskites. Both decomposition of precursor complexes and combustion synthesis routes have been in use for obtaining fine sized-perovskite powders of uniform composition. Of these two methods, the latter one has additional advantages such as maximum energy efficiency, low processing cost and high production rate. The most commonly used fuels in combustion route are glycine, ${ }^{7}$ oxalic acid ${ }^{8}$ and its dihydrazide, ${ }^{9}$ urea, ${ }^{10}$ sucrose,${ }^{11}$ citric acid, ${ }^{12}$ tartaric acid, ${ }^{13}$ etc.

A variety of perovskite materials have been used as anode material for fuel oxidations. Thus for example, Mn-doped $\mathrm{La}(\mathrm{Sr}) \mathrm{CrO}_{3-\delta}{ }^{14}$ has been used successfully 
as anode material for hydrogen oxidation in SOFC configuration. Calcium doped $\mathrm{LaMO}_{3}(\mathrm{M}=\mathrm{Cr}, \mathrm{Fe}, \mathrm{Co}$, $\mathrm{Ni})^{5}$ have been used as anodic material for amperometric sensing of hydrogen peroxide, although the best results were obtained by using $\mathrm{La}_{0.6} \mathrm{Ca}_{0.4} \mathrm{MnO}_{3}$. In another work, $\mathrm{La}_{0.6} \mathrm{Sr}_{0.4} \mathrm{Co}_{0.2} \mathrm{Fe}_{0.8} \mathrm{O}_{3}$ (LSCF6428) has been used as anode material ${ }^{2}$ for methane oxidation for working of an ITSOFC. Various perovskites of the general formula $\mathrm{ARuO}_{3}(\mathrm{~A}=\mathrm{Sr}, \mathrm{Ba}, \mathrm{La})$ are further used as anode material for the oxidation of small organic molecules such as methanol, ethanol and formic acid. ${ }^{15}$ Composite catalysts containing the perovskite lanthanum nickelate and platinum supported on carbon has been tried as anode material from the author's lab for methanol oxidation. ${ }^{16}$ Here, a synergestic effect of increase in oxidation current is observed when perovskite is added to the Pt/C catalyst. However, there are practically no papers dealing with the use of perovskites as anode material for borohydride oxidation and hence the rationality of this work.

Borohydride oxidation occurs at different potentials on different electrodes depending on the work function of the electrode and the ability of borohydride to adsorb on to the surface of the electrode. Alkaline medium is the preferred medium for this reaction as borohydride is not chemically stable in acid media. Many catalysts based on metals, alloys, metal hydride materials, etc. have been used for studying borohydride oxidation. Thus, carbon-supported colloidal Au and colloidal $\mathrm{Au}$ based alloys (Au-Pt, Au-Pd), colloidal Pt and colloidal Pt based alloys (Pt-Ir, Pt-Ni) have been used as anode electrocatalysts for studying borohydride oxidation in direct borohydride fuel cell (DBFC). ${ }^{17,18}$ Among these, Au-Pt, Pt-Ir and Pt-Ni showed appreciable catalytic behaviour towards borohydride oxidation. Nanoparticles of Au and Ag supported on carbon ${ }^{19}$ have also been used as anode electrocatalysts for studying the borohydride oxidation. Between these two, former is reported as promising anode material for direct borohydride fuel cell (DBFC). Hydrogen storage alloy materials of $\mathrm{AB}_{5}$ type has also been tried as an anode electrocatalyst. ${ }^{20,21}$ Thus, $\mathrm{LaNi}_{4.5} \mathrm{Al}_{0.5}$ and Si-doped $\mathrm{LmNi}_{4.78} \mathrm{Mn}_{0.22}$ alloys showed potential catalytic activity towards borohydride oxidation and its hydrolysis.

When electrocatalysts are used for borohydride oxidation, they also aid the unwanted hydrolysis of borohydride reaction which will decrease the current efficiency. However, in the literature, it has been shown that silver while catalyses the borohydride oxidation through eight electron transfer; it will not aid the hydrolysis of borohydride. ${ }^{19}$ Hence, in the present work, undoped and Ag-doped lanthanum chromites have been used as anode materials for borohydride oxidation. We synthesized Ag-doped lanthanum chromites by employing the decomposition of precursor complex route using nitrilotriacetic acid as the complexing ligand and undoped (pure) lanthanum chromite by employing combustion synthesis route using oxalic acid as the fuel. In general, the fuel in combustion synthesis serves two objectives: (i) they are the source of $\mathrm{C}$ and $\mathrm{H}$, the reducing elements (e.g., oxalic acid), which produce $\mathrm{CO}_{2}$ and $\mathrm{H}_{2} \mathrm{O}$ on combustion and liberate heat; (ii) they form complexes with the metal ions thereby promoting homogeneous mixing of the cations in solution. ${ }^{22}$ Lanthanum chromite has been chosen as the perovskite material for this work because $\mathrm{Cr}$ owing to its variable valence character is known to modify the electronic states of the neighbouring atoms of the perovkite catalyst in a mixed way. It is expected that this may aid the borohydride oxidation. The nominal compositions of the Ag-substituted lanthanum chromites prepared are: $\mathrm{LaCr}_{0.25} \mathrm{Ag}_{0.75} \mathrm{O}_{3}$, $\mathrm{LaCr}_{0.4} \mathrm{Ag}_{0.6} \mathrm{O}_{3}, \mathrm{LaCr}_{0.55} \mathrm{Ag}_{0.45} \mathrm{O}_{3}$, and $\mathrm{LaCr}_{0.7} \mathrm{Ag}_{0.3} \mathrm{O}_{3}$. Among these, $\mathrm{LaCr}_{0.4} \mathrm{Ag}_{0.6} \mathrm{O}_{3}$ and $\mathrm{LaCr}_{0.7} \mathrm{Ag}_{0.3} \mathrm{O}_{3}$ alone have shown good XRD pattern corresponding to a perovskite phase in addition to $\mathrm{LaCrO}_{3}$ and hence we restrict our discussion to the comparison of experimental results of these two compounds with the undoped $\mathrm{LaCrO}_{3}$.

\section{Experimental}

\subsection{Starting materials}

Lanthanum chloride (GR Qualigens), Chromium chloride (AR Qualigens), Silver nitrate (AR, CDH), Sodium hydroxide (AR, BDH), Disodium salt of nitrilotriacetic acid (NTA) (Aldrich) were used for the synthesis of $\mathrm{LaCr}_{\mathrm{x}} \mathrm{Ag}_{1-\mathrm{x}} \mathrm{O}_{3}$ perovskite. All aqueous solutions were prepared by using double distilled water obtained from a quartz distillation Unit. Chromium (III) nitrate nonahydrate (99\%, Sigma Aldrich), Lanthanum oxide (99\%, Sigma Aldrich) and oxalic acid (AR Sigma Aldrich) were used for the synthesis of lanthanum chromite.

\subsection{Synthesis procedures}

2.2a Synthesis of $\mathrm{LaCr}_{0.4} \mathrm{Ag}_{0.6} \mathrm{O}_{3}$ and $\mathrm{LaCr}_{0.7} \mathrm{Ag}_{0.3} \mathrm{O}_{3}$ : The synthesis of the perovskites $\mathrm{LaCr}_{0.4} \mathrm{Ag}_{0.6} \mathrm{O}_{3}$ and $\mathrm{LaCr}_{0.7} \mathrm{Ag}_{0.3} \mathrm{O}_{3}$ were carried out by decomposing the precursor complex of nitrilotriacetic acid (NTA) with $\mathrm{La}, \mathrm{Cr}$ and $\mathrm{Ag}$ of suitable stoichiometry, formed from 
the reaction of corresponding metal hydroxides with NTA. The starting materials in the preparation of the precursor complex were $\mathrm{LaCl}_{3}, \mathrm{CrCl}_{3}, \mathrm{AgNO}_{3}$. As the anions were not same in all the above starting material, in order to avoid the interference of chloride during the formation of hydroxides of various metals, we have proceeded with the synthesis of corresponding hydroxides as follows: Here, we give the procedure adopted for preparing $\mathrm{LaCr}_{0.4} \mathrm{Ag}_{0.6} \mathrm{O}_{3}$. For other compositions of the perovskites, they are similar except that the stoichiometric amounts of individual starting materials differ viz., $\mathrm{LaCl}_{3}, \mathrm{CrCl}_{3}$ and $\mathrm{AgNO}_{3}$.

Initially, $0.01 \mathrm{~mol}$ of $\mathrm{LaCl}_{3}, 0.004 \mathrm{~mol}$ of $\mathrm{CrCl}_{3}$ and $0.006 \mathrm{~mol}$ of $\mathrm{AgNO}_{3}$ (mol ratio of $\mathrm{La}: \mathrm{Cr}: \mathrm{Ag}=$ 1:0.4:0.6) in aqueous media were prepared separately under constant stirring. To each one of these, $1.0 \mathrm{~N}$ $\mathrm{NaOH}$ (excess) is added and heated to $80^{\circ} \mathrm{C}$ to ensure that the precipitation of hydroxides of corresponding metals viz., $\mathrm{La}(\mathrm{OH})_{3}, \mathrm{Cr}(\mathrm{OH})_{3}$ and $\mathrm{AgOH}$. The precipitates of $\mathrm{La}(\mathrm{OH})_{3}, \mathrm{Cr}(\mathrm{OH})_{3}$ and $\mathrm{AgOH}$ were filtered and washed with copious amounts of water to remove excess amount of chloride and then dried in an air oven at $80^{\circ} \mathrm{C}$.

The formation of hydroxides of $\mathrm{La}, \mathrm{Cr}$ and $\mathrm{Ag}$ are represented as follows

$$
\begin{aligned}
& \mathrm{LaCl}_{3}+3 \mathrm{NaOH} \longrightarrow \mathrm{La}(\mathrm{OH})_{3} \downarrow+3 \mathrm{NaCl} \\
& \mathrm{CrCl}_{3}+3 \mathrm{NaOH} \longrightarrow \mathrm{Cr}(\mathrm{OH})_{3} \downarrow+3 \mathrm{NaCl} \\
& \mathrm{AgNO}_{3}+\mathrm{NaOH} \longrightarrow \mathrm{Ag}(\mathrm{OH}) \downarrow+\mathrm{NaNO}_{3} .
\end{aligned}
$$

In the next step, $0.261 \mathrm{M}$ nitrilotriacetic acid (NTA) in $\mathrm{NaOH}$ solution $(16.216 \mathrm{~g}$ of $\mathrm{NTA} / 1 \mathrm{M} \mathrm{NaOH})$ was added to the above precipitates and heated to $80^{\circ} \mathrm{C}$ for about $4 \mathrm{~h}$ separately. Then all the precipitates were filtered individually using a Millipore membrane filter paper $(0.45 \mu$ pore size $)$ and then dried at $80^{\circ} \mathrm{C}$ for $2 \mathrm{~h}$. The possible reaction involved was the transformation of metal ion from hydroxide form to appropriate NTA complex represented as

$$
\begin{aligned}
& \mathrm{La}^{3+}+[\mathrm{NTA}]^{3-} \longrightarrow[\mathrm{La}(\mathrm{NTA})] \\
& \mathrm{Cr}^{3+}+[\mathrm{NTA}]^{3-} \longrightarrow[\mathrm{Cr}(\mathrm{NTA})] \\
& \mathrm{Ag}^{+}+[\mathrm{NTA}]^{3-} \longrightarrow[\mathrm{Ag}(\mathrm{NTA})]^{2-} .
\end{aligned}
$$

The possible structure of NTA complexes of $\mathrm{La}, \mathrm{Cr}$ and $\mathrm{Ag}$ are shown in figure 1.

Subsequently, the individual precipitates were mixed together and ground well in a mortar with pestle. These precipitates were then kept in a muffle furnace. The temperature was raised to $900^{\circ} \mathrm{C}$ at a slow heating rate $\left(5^{\circ} \mathrm{C} / \mathrm{min}\right)$ to remove any water of crystallization and also to facilitate the decomposition of organic components and maintained for $7 \mathrm{~h}$ to promote the formation of perovskite.
$2.2 \mathrm{~b}$ Synthesis of undoped or pure $\mathrm{LaCrO}_{3}$ : Lanthanum nitrate solution (net amount of solute after reaction $=0.05 \mathrm{~mol}$ ), required for the preparation of $\mathrm{LaCrO}_{3}$ was prepared by treating $0.025 \mathrm{~mol}$ of $\mathrm{La}_{2} \mathrm{O}_{3}$ with $(10 \mathrm{ml}, 15.8 \mathrm{M})$ concentrated nitric acid. To this solution, $0.05 \mathrm{~mol}$ of $\mathrm{Cr}\left(\mathrm{NO}_{3}\right)_{3} \cdot 9 \mathrm{H}_{2} \mathrm{O}$ and $0.1 \mathrm{~mol}$ of oxalic acid were mixed in which the mol ratio of metal nitrates and oxalic acid were 1:1. The mixture was heated on a hot plate. Gel formation was achieved at $80^{\circ} \mathrm{C}$. On further heating to $100^{\circ} \mathrm{C}$, the gel became a greyish-green coloured powder. This assynthesized powder presumably may consist of products that were formed due to the incomplete combustion viz., some un-reacted organic decomposition products, some organic complexes and oxides of $\mathrm{La}$ and $\mathrm{Cr}$, etc. and hence this can also be called as a precursor intermediate. To get a single phase $\mathrm{LaCrO}_{3}$ perovskite, this powder was then calcined in a muffle furnace at $450^{\circ} \mathrm{C}$ for $2 \mathrm{~h}$ and then at $900^{\circ} \mathrm{C}$ for $10 \mathrm{~h}$ to obtain a pure perovskite phase of yellowish green $\mathrm{LaCrO}_{3}(\mathrm{cal}$ cined powder). The overall reaction in the formation of perovskite phase is as given

$$
\begin{aligned}
& 2 \mathrm{La}\left(\mathrm{NO}_{3}\right)_{3}+2 \mathrm{Cr}\left(\mathrm{NO}_{3}\right)_{3}+6 \mathrm{H}_{2} \mathrm{C}_{2} \mathrm{O}_{4} \\
& \longrightarrow \\
& 2 \mathrm{LaCrO}_{3}+6 \mathrm{H}_{2} \mathrm{O}+12 \mathrm{NO}_{2} \uparrow+12 \mathrm{CO}_{2} \uparrow .
\end{aligned}
$$

\subsection{Characterization}

TGA-DTA was performed for as-synthesized powder (undoped $\mathrm{LaCrO}_{3}$ ) using a SDT Q600 (TA-instrument) thermal analyzer with a heating rate of $20^{\circ} \mathrm{C} / \mathrm{min}$ in air atmosphere. XRD patterns of the calcined perovskite powders were obtained by using a Phililips X' pert pro PANalytical X-ray diffractometer that uses $\mathrm{Cu}-\mathrm{K}_{\alpha}$ line as the source radiation at $0.154060 \mathrm{~nm}$. The step size of the $2 \theta$ scans was 0.0170 . SEM images of the calcined powders were obtained by using HITACHI S-3000H microscope at $20 \mathrm{kV}$ accelerating voltage.

\subsection{Electrochemical characterization}

The electrochemical characterization of the catalysts (calcined samples) was done by using a BAS Model $100 \mathrm{~A}$ electrochemical analyzer. A three electrode system with perovskite catalyst coated glassy carbon as working electrode, $\mathrm{Hg} / \mathrm{HgO}, 30 \% \mathrm{KOH}$ (MOE) as reference electrode and a $1 \mathrm{~cm}^{2} \mathrm{Pt}$ foil as the counter electrode was employed for studying the borohydride electro-oxidation. In all our experiments we have used sodium borohydride for borohydride electro-oxidation. The catalyst coating was done on a $3.0 \mathrm{~mm}$ diameter 


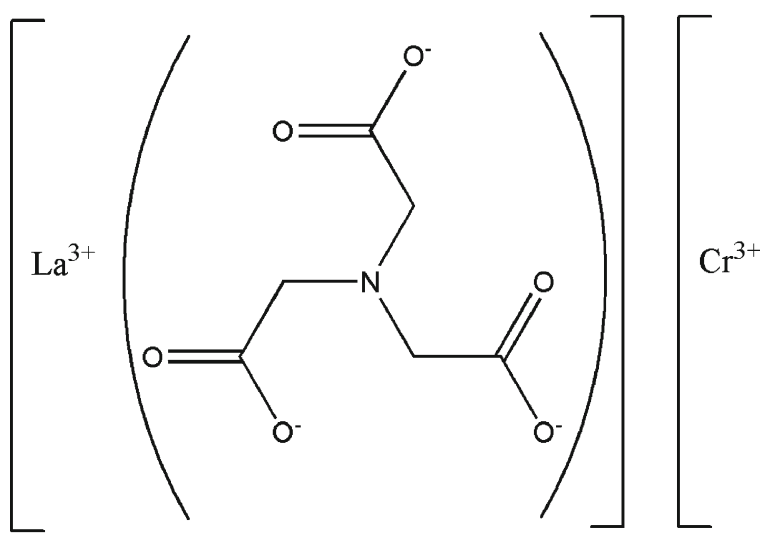

(a)

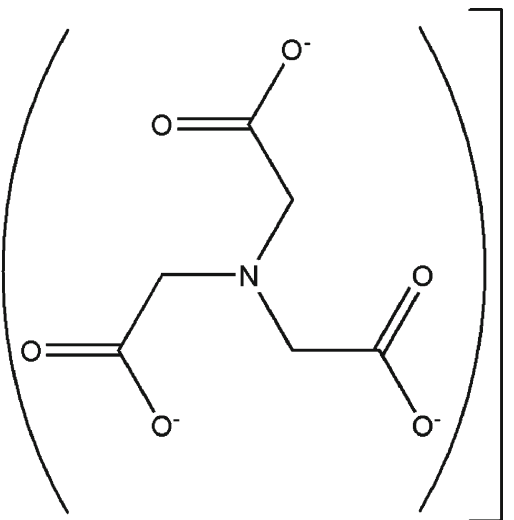

(b)

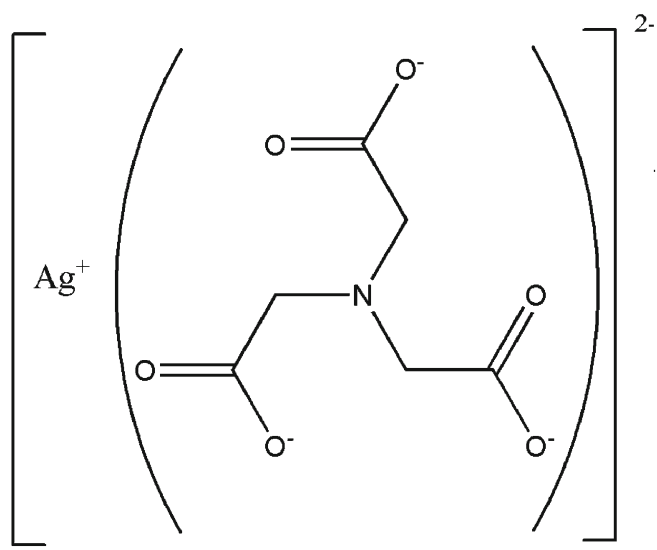

(c)

Figure 1. Structure of NTA complex of (a) $\mathrm{La},(\mathbf{b}) \mathrm{Cr}$ and (c) Ag.

glassy carbon (GC) disk substrate polished to a mirror finish by using $5 / 0$ and $6 / 0$ emery papers for about half an hour. Prior to this, the catalyst ink was prepared by ultrasonically dispersing $10 \mathrm{mg}$ of the catalyst in a mixture of $1000 \mu \mathrm{l}$ of milli-Q water and $1000 \mu \mathrm{l}$ of $5 \%$ nafion solution for about $45 \mathrm{~min} .10 \mu \mathrm{l}$ of the catalyst ink was pipetted on the GC substrate and kept under a $60 \mathrm{~W}$-tungsten filament lamp and dried overnight.

A potential cycling was carried out (10 to 20 times) in the range $-1.0 \mathrm{~V}$ to $1.0 \mathrm{~V}$ vs MOE to activate the catalyst surface. Cyclic voltammograms were carried out at $20 \mathrm{mV} \mathrm{s}^{-1}$ to study the oxidation of borohydride on the different perovskites coated GC electrodes at $0.7 \mathrm{mgcm}^{-2}$ catalyst loading. All potentials were referred to MOE scale.

\section{Results and discussion}

\subsection{TGA-DTA characterization}

The TGA/DTA curve for the as-synthesized $\mathrm{LaCrO}_{3}$ is shown in figure 2. It can bee seen from this figure that there are four weight loss regions viz., 50$100^{\circ} \mathrm{C}$ (steep) $100-225^{\circ} \mathrm{C}$ (large), $225-345^{\circ} \mathrm{C}$ (fairly large), $345-405^{\circ} \mathrm{C}$ (very steep) and $405-750^{\circ} \mathrm{C}$ (almost negligible). The weight loss region from 50 to $100^{\circ} \mathrm{C}$

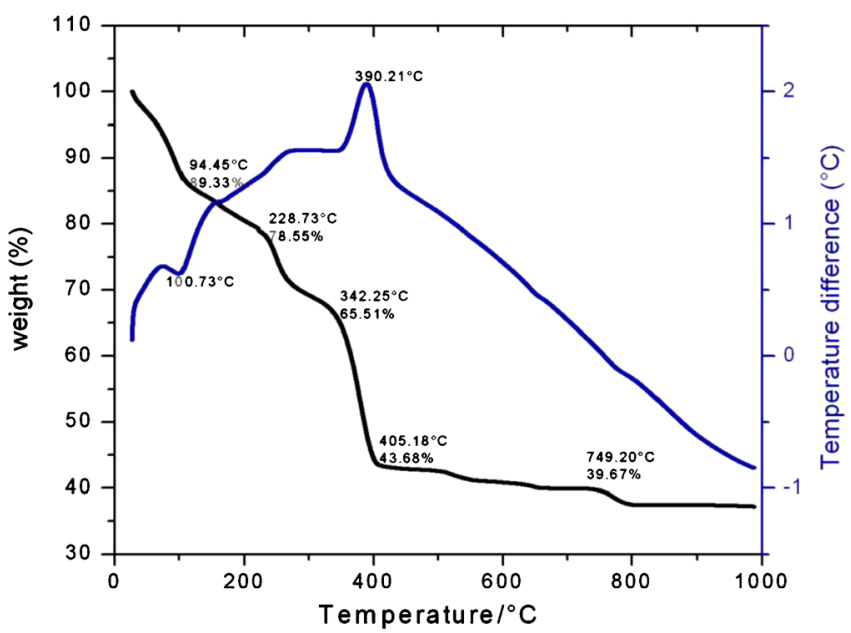

Figure 2. TGA-DTA curve for the as-synthesized $\mathrm{LaCrO}_{3}$ powder. 
may be due to the loss of moisture from the precursor intermediate. The weight loss region from 100 to $225^{\circ} \mathrm{C}$ may be due to the loss of coordinated water. The weight loss region between 225 and $345^{\circ} \mathrm{C}$ may be due to the disconnection of bond between metal and carboxyl groups of the precursor intermediate. The next region from 345 to $405^{\circ} \mathrm{C}$ may be due to the formation of individual/mixed oxides and the further weight loss from 405 to $750^{\circ} \mathrm{C}$ may be due to the rearrangement of individual oxides leading to the formation of perovskite. Since there is no further weight loss beyond $750^{\circ} \mathrm{C}$ and up to $1000^{\circ} \mathrm{C}$, it is suggested that the perovskite phase might have been formed completely beyond $750^{\circ} \mathrm{C}$. These results are also corroborated by the DTA results. In DTA curve, the endothermic peak at $100^{\circ} \mathrm{C}$ may be due to loss of moisture. The strong exothermic peak at $390^{\circ} \mathrm{C}$ may be due to the decomposition of precursor intermediate to the individual oxides and subsequently the commencement of the formation of perovskite phase. ${ }^{23}$ These results are used to fix the temperature for calcination process to get perovskite powder. As the TGA and DTA involve dynamic heating of a small amount of sample, to synthesize sizeable quantity of catalyst powders, the calcination is done at the set temperatures for longer time. Thus, we have chosen $450^{\circ} \mathrm{C}$ for two hours to completely decompose all organic compounds/complexes of the as-synthesized powder and then heat the resulting powder to $900^{\circ} \mathrm{C}$ for $10 \mathrm{~h}$. This resulted in the formation of pure perovskite phase of $\mathrm{LaCrO}_{3}$.

\subsection{XRD characterization}

The XRD pattern for calcined powder of undoped $\mathrm{LaCrO}_{3}$ is shown in figure 3. The pattern confirms the formation of pure perovskite phase. The XRD patterns of the calcined powders of Ag-doped lanthanum chromites are shown in figure 4 along with that of $\mathrm{LaCrO}_{3}$ (undoped). The peaks are sufficiently sharp and indicate the crystalline nature of the material. The peak identification for different XRD reflections for the above chromites is shown in table 1 . The $d$-spacing values for the first three strong peaks for all the calcined powders occurred around $2.743 \AA$, $1.942 \AA$ and $1.5842 \AA$ and they correspond to the lattice planes (110), (200) and (211), respectively. Further, when a comparison of these XRD peaks is made with the standard XRD pattern of $\mathrm{LaCrO}_{3}$ (JCPDS file No. 74-1961), ${ }^{24}$ they corresponded to a cubic crystal system ( $P m_{-} 3 m$ space group). Although a pure perovskite phase is seen for $\mathrm{LaCrO}_{3}$ synthesized by oxalic acid route, the Ag-doped lanthanum chromites show additional peaks corresponding to that of $\mathrm{La}_{14} \mathrm{Ag}_{15}$ and

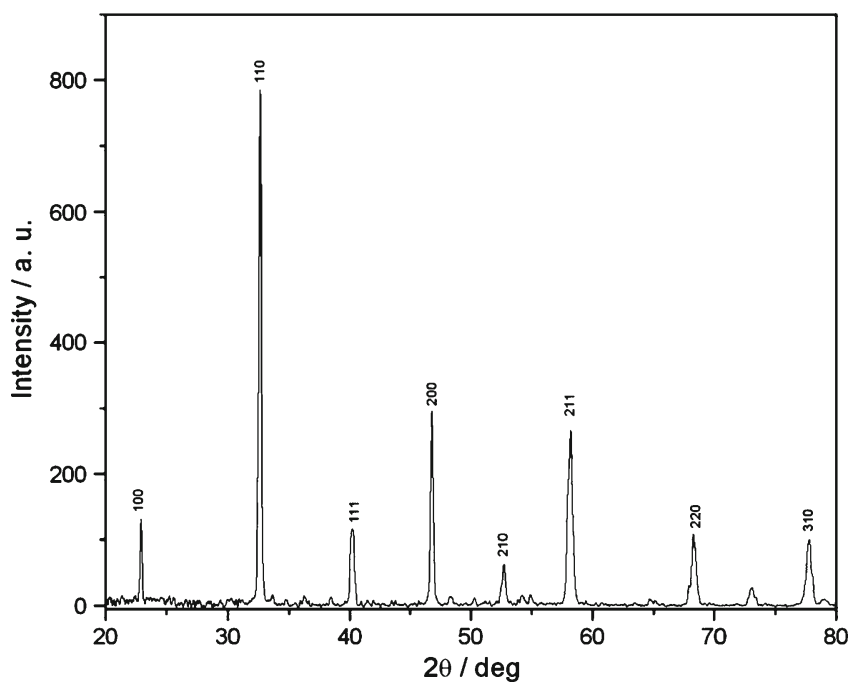

Figure 3. XRD pattern for the calcined powder $\left(\mathrm{LaCrO}_{3}\right)$ at $900^{\circ} \mathrm{C}$ for $10 \mathrm{~h}$.

individual oxides of $\mathrm{La}, \mathrm{Cr}$ and $\mathrm{Ag}$ which are impurity phases present in small quantities. In addition to this, two small peaks are observed for both $\mathrm{LaCr}_{0.4} \mathrm{Ag}_{0.6} \mathrm{O}_{3}$ and $\mathrm{LaCr}_{0.7} \mathrm{Ag}_{0.3} \mathrm{O}_{3}$ in which the peak at $2 \theta=43^{\circ}$ and the other one at $2 \theta=65^{\circ}$ are indexed to (200) and (220) planes of pure silver, respectively (JCPDS file No. 04-0783). But these two peaks correspond to the lowest intensity peaks of silver. Expectedly, these peaks are absent in the undoped lanthanum chromite thereby confirming the presence of silver in silver-doped lanthanum chromites.

In addition, the $100 \%$ intensity peaks of $\mathrm{Ag}, \mathrm{AgO}$ and $\mathrm{Ag}_{2} \mathrm{O}$ are not detected in both the XRD pattern

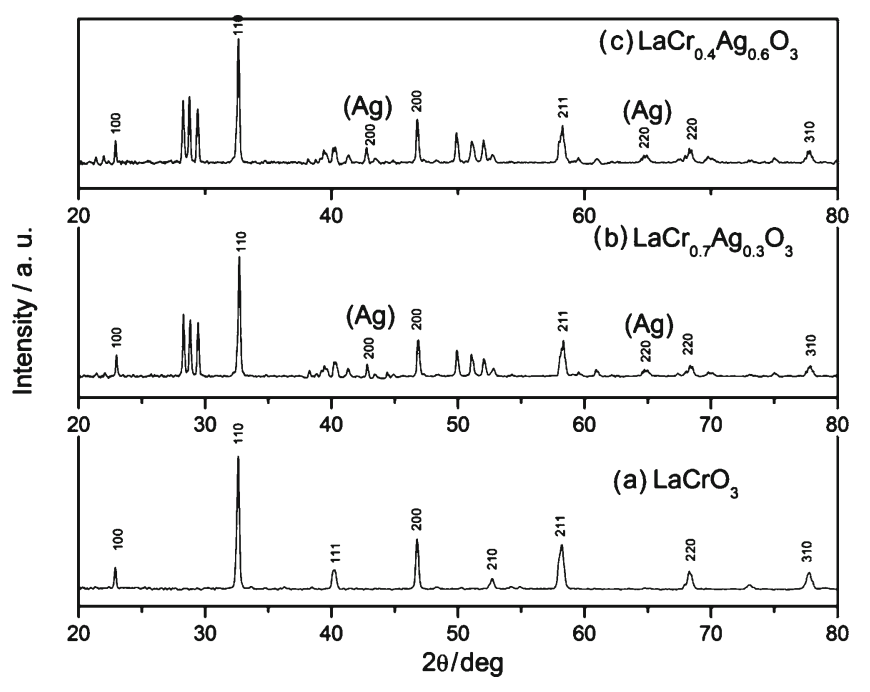

Figure 4. $\mathrm{XRD}$ patterns of (a) $\mathrm{LaCrO}_{3}$, (b) $\mathrm{LaCr}_{0.7}$ $\mathrm{Ag}_{0.3} \mathrm{O}_{3}$ and (c) $\mathrm{LaCr}_{0.4} \mathrm{Ag}_{0.6} \mathrm{O}_{3}$. 
Table 1. Phase identification from XRD data (perovskite with a cubic structure).

\begin{tabular}{|c|c|c|c|c|}
\hline S.No & $\mathrm{LaCrO}_{3}$ & $\mathrm{LaCr}_{0.7} \mathrm{Ag}_{0.3} \mathrm{O}_{3}$ & $\mathrm{LaCr}_{0.4} \mathrm{Ag}_{0.6} \mathrm{O}_{3}$ & Plane identification \\
\hline \multicolumn{5}{|c|}{$d$ spacing $\AA$} \\
\hline 1 & 3.88224 & 3.86662 & 3.88039 & 100 \\
\hline 2 & 2.74279 & 2.73933 & 2.74426 & 110 \\
\hline 3 & 2.24409 & 2.24131 & 2.24402 & 111 \\
\hline 4 & 1.94274 & 1.94069 & 1.94324 & 200 \\
\hline 5 & 1.73570 & 1.73235 & - & 210 \\
\hline 6 & 1.58417 & 1.58109 & 1.58282 & 211 \\
\hline 7 & 1.37320 & 1.37115 & 1.37221 & 220 \\
\hline \multirow[t]{4}{*}{8} & 1.22849 & 1.22745 & 1.22834 & 310 \\
\hline & 3.8854 & 3.8763 & 3.8819 & Cell parameter ' $a$ ' $\AA$ \\
\hline & 23.34 & 45.32 & 46.38 & Average particle size from \\
\hline & & & & Debye-Scherrer equation (nm) \\
\hline
\end{tabular}

of $\mathrm{LaCr}_{0.4} \mathrm{Ag}_{0.6} \mathrm{O}_{3}$ and $\mathrm{LaCr}_{0.7} \mathrm{Ag}_{0.3} \mathrm{O}_{3}$. If silver or its oxides are just acting as a mere mixture with lanthanum chromites, the $100 \%$ peaks of them should have been reflected in the XRD pattern. Due to the absence of $100 \%$ characteristic peaks of silver and its oxides in the PXRD pattern of the Ag-doped chromites we have synthesized in the present work, we conclude that $\mathrm{LaCr}_{0.4} \mathrm{Ag}_{0.6} \mathrm{O}_{3}$ and $\mathrm{LaCr}_{0.7} \mathrm{Ag}_{0.3} \mathrm{O}_{3}$ are formed although we are not sure of their exact crystalline structure.

The lattice parameters ' $a$ ' for the cubic structure of perovskite material are found by using the relation applicable for each of the representative peak.

$$
\frac{1}{d_{\mathrm{hkl}}^{2}}=\frac{h^{2}+k^{2}+l^{2}}{a^{2}} \longrightarrow,
$$

where $d_{\mathrm{hkl}}$ is the lattice plane spacing or $d$-spacing of a lattice with $\mathrm{hkl}$ as the miller indices of the plane under consideration. The average value of the lattice parameter ' $a$ ' for each of the above Ag-doped and undoped lanthanum chromite is calculated by taking the average of cell parameters corresponding to each of the reflections of the material. The average lattice parameters for $\mathrm{LaCrO}_{3}, \mathrm{LaCr}_{0.7} \mathrm{Ag}_{0.3} \mathrm{O}_{3}$ and $\mathrm{LaCr}_{0.4} \mathrm{Ag}_{0.6} \mathrm{O}_{3}$ are found to be $a=b=c=3.8854 \AA$, $3.8763 \AA$ and $3.8819 \AA$, respectively.

The average particle size ' $t$ ' is obtained using the Debye-Scherrer formula

$$
t=0.9 \lambda / \beta \cos \theta \longrightarrow,
$$

where $t$ is the thickness or size of the particle $(\mathrm{nm}) ; \lambda$ is the wavelength of the X-rays used $(=1.5405 \AA=$ $0.15405 \mathrm{~nm}) ; \beta$ is the Full Width at Half Maximum of the peak (FWHM) in radians, the peaks used for calculations being 110, 111, 211, 220 and 310 planes at corresponding $2 \theta$ values in degrees; $\theta$ is the Bragg diffraction angle in degrees. We have taken the average of the particle sizes obtained for each of the above planes for each perovskite material and the same is indicated in table 1. It can be seen from this table that the average particle sizes of the different perovskite materials range between $23.3 \mathrm{~nm}$ and $46.4 \mathrm{~nm}$.

\subsection{SEM investigation}

The microstructures for all the three undoped and Agdoped lanthanum chromites are shown in figure $5 \mathrm{a}-\mathrm{c}$.

In all these powders, the particle sizes are clearly in the nanometer to micrometer dimensions. The surface morphology of all the three powders is similar and show sharp bright grains (of nanometer dimension) of varying distributions spread on flake-like material (particles of micrometer dimension) of no regular shape interspersed with voids. It appears that the flake-like particles in turn are assemblies of small particles. The average particle size of the powders is around $1 \mu \mathrm{m}$. The surface morphology of Ag-doped lanthanum chromites having higher silver content (figure 5c) show brighter grains with sharp edges spread over larger flake-like particles with dull appearance as compared to the undoped one. Since these Ag-doped lanthanum chromites contain both perovskite phase and individual oxide phases, we presume that the former phase is obtained at the exterior and the latter phases present as flakes in the interior portion. These flakes could have been formed by the particles of individual oxides with no sharp edges in any one of the particles and could have got agglomerated in the form of flakes.

\subsection{Electrochemical characterization}

The cyclic voltammograms for the blank and $100 \mathrm{mM}$ sodium borohydride concentration on both undoped and 


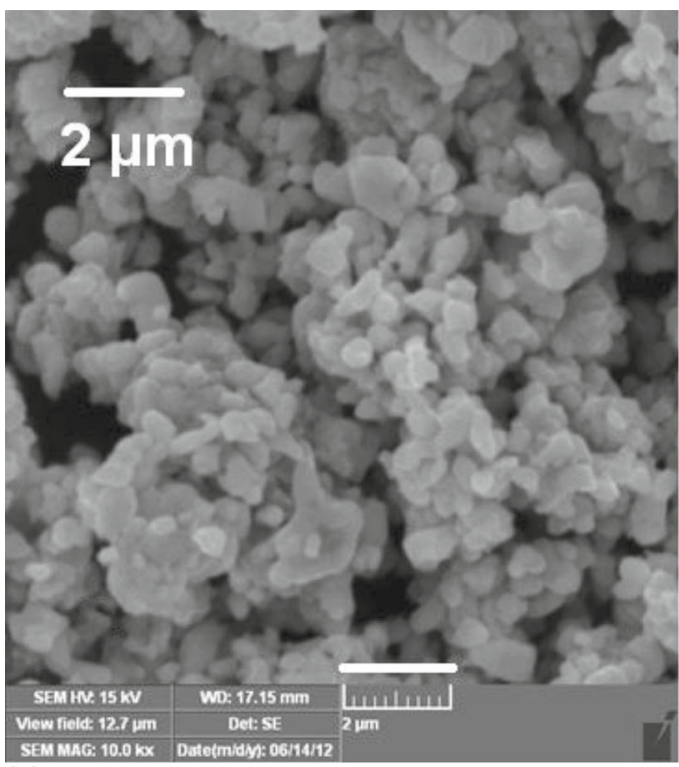

(a)

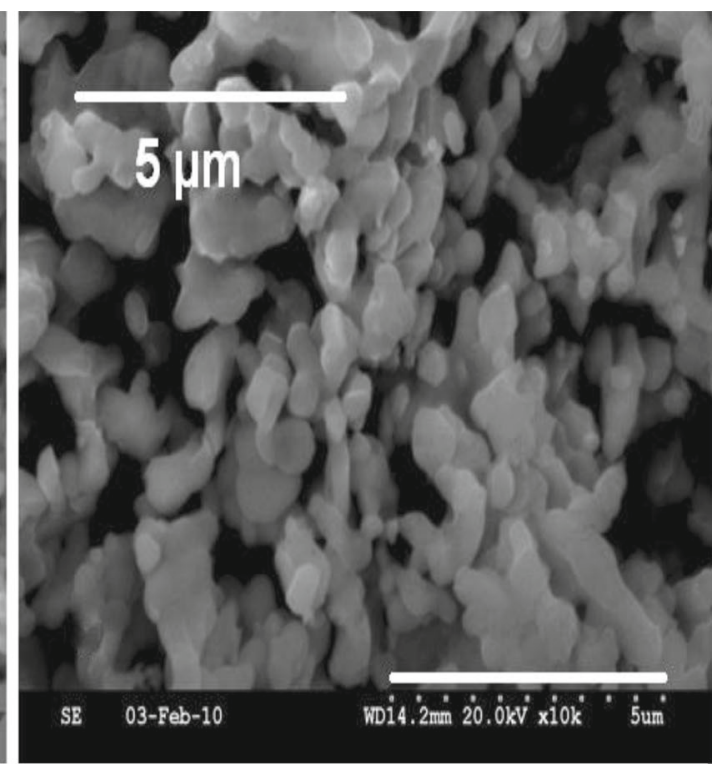

(b)

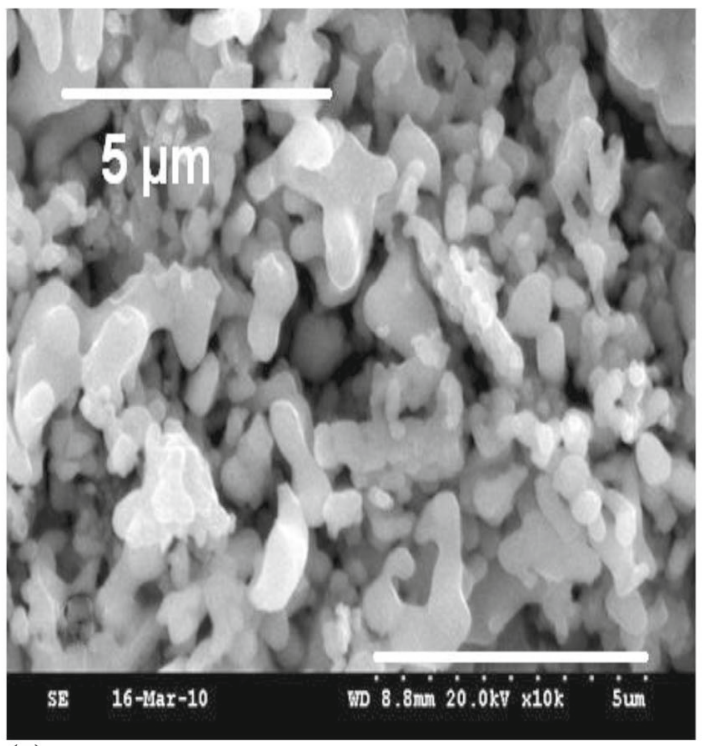

(c)

Figure 5. $\mathrm{SEM}$ images of (a) $\mathrm{LaCrO}_{3}$, (b) $\mathrm{LaCr}_{0.7} \mathrm{Ag}_{0.3} \mathrm{O}_{3}$ and (c) $\mathrm{LaCr}_{0.4} \mathrm{Ag}_{0.6} \mathrm{O}_{3}$.

Ag-doped lanthanum chromites are shown separately in figure 6a-d. It can be seen from these figures that the peak current did not change much when borohydride was added to sufficient extent $(100 \mathrm{mM})$ both for the undoped and $\mathrm{Ag}$-doped lanthanum chromites except for the composition $\mathrm{LaCr}_{0.4} \mathrm{Ag}_{0.6} \mathrm{O}_{3}$. The cyclic voltammogram for the blank in the undoped lanthanum chromite did not show any peak close to $-0.4 \mathrm{~V} \mathrm{Vs}$ $\operatorname{MOE}(-0.3 \mathrm{~V}$ Vs SHE), while the Ag-doped ones (viz., $\mathrm{LaCr}_{0.25} \mathrm{Ag}_{0.75} \mathrm{O}_{3}, \mathrm{LaCr}_{0.4} \mathrm{Ag}_{0.6} \mathrm{O}_{3}$ and $\mathrm{LaCr}_{0.7} \mathrm{Ag}_{0.3} \mathrm{O}_{3}$ ) show a small peak at this potential. This peak has been attributed to the formation of hydroxide of silver by Chatnet et al. ${ }^{25}$ during their study on polycrystalline silver.
Since Ag is part of the perovskite structure, we presume that this small peak is due to the formation of silver hydroxide. When additions of sodium borohydride are made with $\mathrm{LaCr}_{0.4} \mathrm{Ag}_{0.6} \mathrm{O}_{3}$ electrode, the small peak became a shoulder peak along with borohydride oxidation current peak trace. Since the shoulder current merges along with the borohydride oxidation current, the on-set current for borohydride oxidation could not be precisely seen and it can be assumed to be starting after this shoulder peak potential which occurs around $-0.5 \mathrm{~V}$ v/s MOE ( $-0.4 \mathrm{~V}$ v/s SHE). This potential corresponds to the potential of zero charge on $\mathrm{Ag}$ as suggested by Chatnet et al. ${ }^{25}$ where the formation of $\mathrm{AgOH}$ on Ag occur. In view of the closeness of on-set potential 

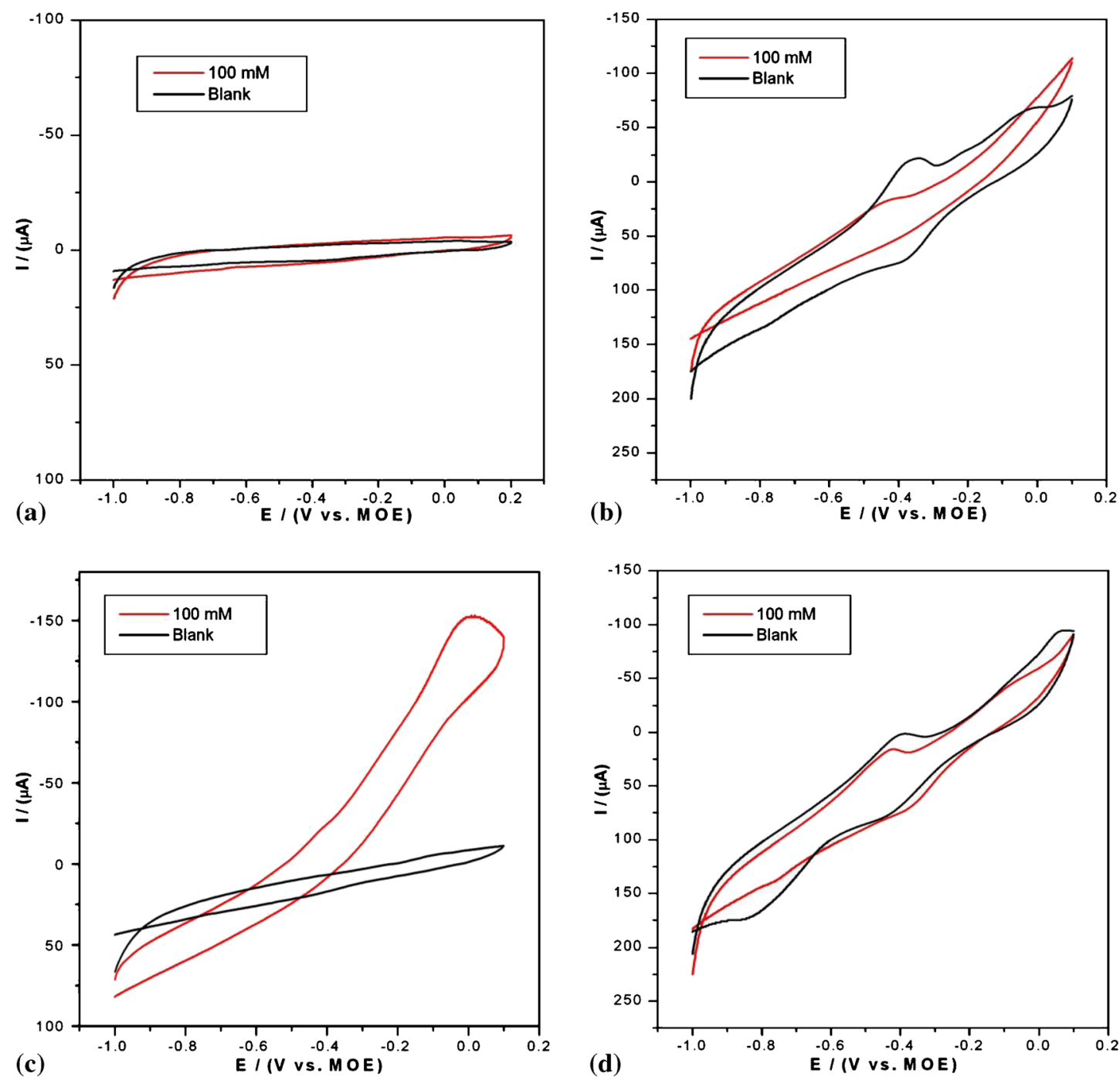

Figure 6. Comparison of cyclic voltammograms for $100 \mathrm{mM}$ sodium borohydride oxidation on (a) $\mathrm{LaCrO}_{3}$, (b) $\mathrm{LaCr}_{0.7} \mathrm{Ag}_{0.3} \mathrm{O}_{3}$, (c) $\mathrm{LaCr}_{0.4} \mathrm{Ag}_{0.6} \mathrm{O}_{3}$ and (d) $\mathrm{LaCr}_{0.25} \mathrm{Ag}_{0.75} \mathrm{O}_{3}$ coated $\mathrm{GC}$ electrode $\left(0.7 \mathrm{mgcm}^{-2}\right)$ in $30 \% \mathrm{KOH}$ solution and sweep rate $=20 \mathrm{mV} \mathrm{s}^{-1}$.

of borohydride oxidation on $\mathrm{Ag}$ and $\mathrm{LaCr}_{0.4} \mathrm{Ag}_{0.6} \mathrm{O}_{3}$, the silver present in $\mathrm{LaCr}_{0.4} \mathrm{Ag}_{0.6} \mathrm{O}_{3}$ can be considered to be transformed as moist silver oxide $(\mathrm{AgOH})$ that behaves as a catalytic surface over which borohydride oxidation occurs.

The peak currents for borohydride oxidation on $\mathrm{LaCrO}_{3}$ and $\mathrm{LaCr}_{0.4} \mathrm{Ag}_{0.6} \mathrm{O}_{3}$ electrodes occur at potentials around -0.5 and $+0.005 \mathrm{~V}(\mathrm{v} / \mathrm{s} \mathrm{Hg} / \mathrm{HgO}, 30 \%$ $\mathrm{KOH})$ which is equivalent to $-0.4 \mathrm{~V}$ and $+0.105 \mathrm{~V}$ $\mathrm{v} / \mathrm{s}$ SHE, respectively. On the other hand, the onset of borohydride oxidation occurs close to the potential of zero charge of $\mathrm{Ag}$ viz., $-0.4 \mathrm{~V}$ v/s SHE and that peak current occurs at $-0.2 \mathrm{~V}$ v/s SHE. ${ }^{25}$ Compared to this, the peak current for borohydride oxidation on $\mathrm{LaCr}_{0.4} \mathrm{Ag}_{0.6} \mathrm{O}_{3}$ electrode occurs at more positive potentials indicating difficulty of oxidation relative to $\mathrm{Ag}$ catalyst. Further, even though the onset of borohydride oxidation occurs in considerable negative values, the peak current occurs after nearly $-0.4 \mathrm{~V}$. In addition, since the cyclic voltamogramms do not show any peak in the reverse scan of the potential, this is indicative of an irreversible behaviour of borohydride oxidation on this mixed oxide electrode. This may be due to the difficulty of borohydride ion to approach the $\mathrm{Ag}$ present in the $\mathrm{B}$ site of the perovskite material which gives rise to the overpotential.

The possible mechanism for borohydride oxidation on Ag-doped lanthanum chromite is

$$
\begin{aligned}
& \mathrm{BH}_{4}^{-}+8 \mathrm{OH}^{-} \rightarrow \mathrm{BO}_{2}^{-}+6 \mathrm{H}_{2} \mathrm{O}+8 \mathrm{e}^{-} \\
& \mathrm{E}^{\circ}=-1.24 \mathrm{~V} \text { versus } \mathrm{SHE}
\end{aligned}
$$

because $\mathrm{Ag}$ does not promote the hydrolysis of borohydride ${ }^{19}$ and further favours direct borohydride 

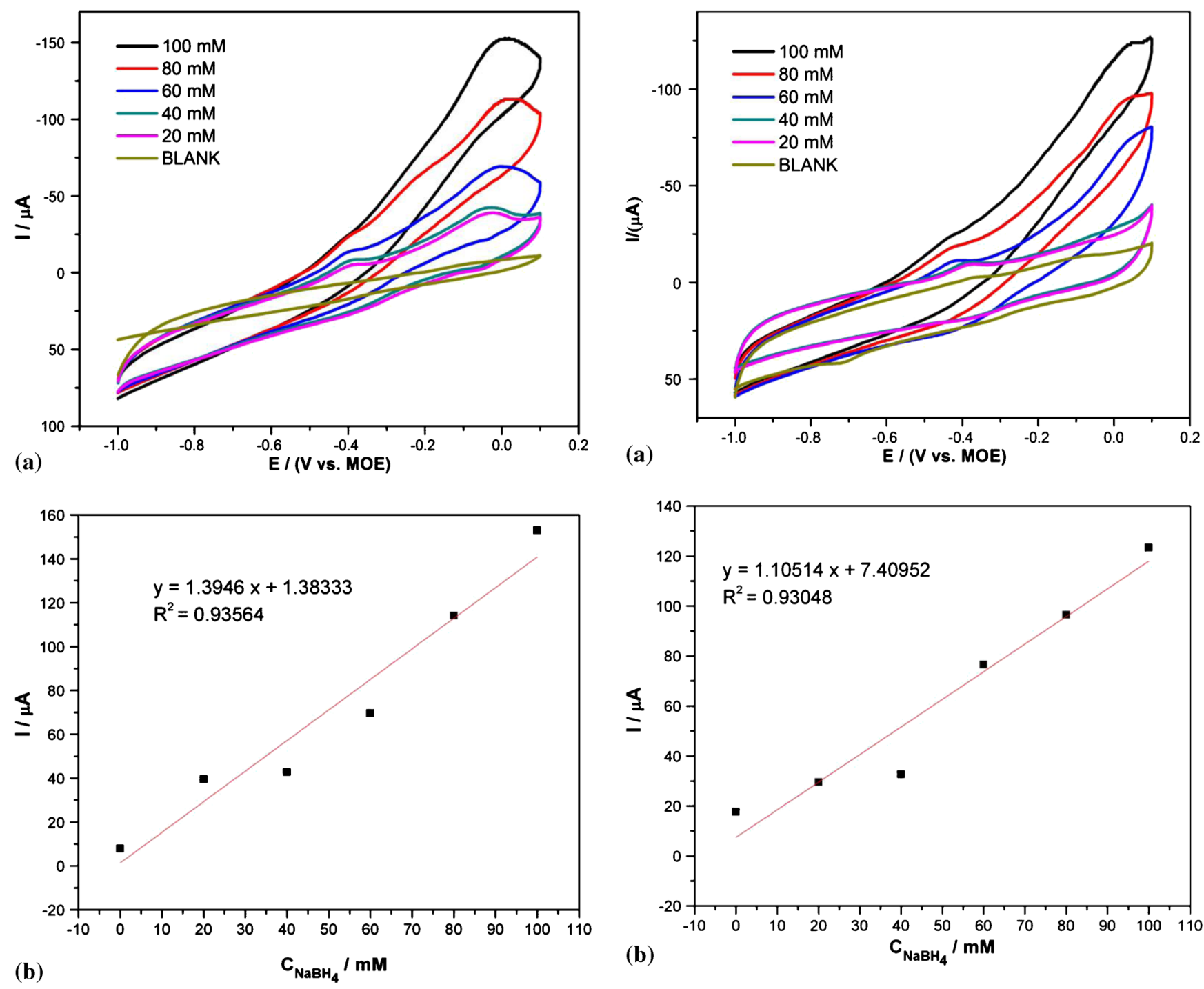

Figure 7. (a) Cyclic voltammogram and (b) calibration plot for the oxidation of $\mathrm{NaBH}_{4}$ at various concentrations on $\mathrm{LaCr}_{0.4} \mathrm{Ag}_{0.6} \mathrm{O}_{3}$ coated $\mathrm{GC}$ electrode $\left(0.7 \mathrm{mgcm}^{-2}\right)$ in $30 \%$ $\mathrm{KOH}$ solution and sweep rate $=20 \mathrm{mV} \mathrm{s}^{-1}$.

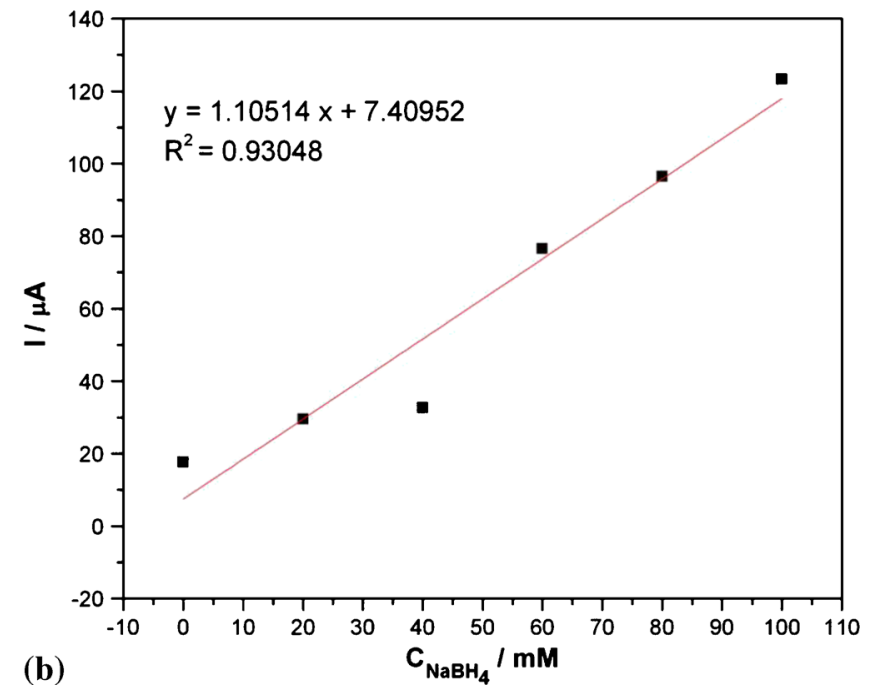

Figure 8. (a) Cyclic voltammogram and (b) calibration plot for the oxidation of $\mathrm{NaBH}_{4}$ at various concentrations on $\mathrm{LaCr}_{0.4} \mathrm{Ag}_{0.6} \mathrm{O}_{3}$ coated GC electrode $\left(2.1 \mathrm{mgcm}^{-2}\right)$ in $30 \%$ $\mathrm{KOH}$ solution and sweep rate $=20 \mathrm{mV} \mathrm{s}^{-1}$.

oxidation especially at higher concentrations of borohydride.

3.4a Concentration effects on borohydride oxidation on $\mathrm{LaCr}_{0.4} \mathrm{Ag}_{0.6} \mathrm{O}_{3}$ : To study the concentration effects, cyclic voltammograms were performed at various concentrations of sodium borohydride in $30 \%$ $\mathrm{KOH}$ (20 mM to $100 \mathrm{mM}$ ) and blank and the same is shown in figure 7a. A calibration plot is also shown in figure $7 \mathrm{~b}$. It can be seen from this figure that the peak current increases with increasing concentration of sodium borohydride in a fairly linear way except in the initial stages. The slope of the linear fit gives the sensitivity of the peak current towards borohydride oxidation, which comes to $1.3946 \mu \mathrm{A} / \mathrm{mM}$.

3.4b Effect of increased catalyst loading: When the catalyst loading was increased from $0.7 \mathrm{mgcm}^{-2}$ to $2.1 \mathrm{mgcm}^{-2}$, there was not much improvement in sensitivity (figure 8a and b). In fact, there was a slight decrease in sensitivity.

\section{Conclusion}

Ag doping in lanthanum chromites was attempted to develop catalysts for borohydride oxidation. However, out of the four compositions prepared, only two compositions have formed the perovskite phases viz., $\mathrm{LaCr}_{0.7} \mathrm{Ag}_{0.3} \mathrm{O}_{3}$ and $\mathrm{LaCr}_{0.4} \mathrm{Ag}_{0.6} \mathrm{O}_{3}$. Out of these two, only $\mathrm{LaCr}_{0.4} \mathrm{Ag}_{0.6} \mathrm{O}_{3}$ has shown some limited activity towards borohydride oxidation. Increased catalyst 
loading did not show any improvement in the sensitivity for borohydride oxidation. Additional work needs to be carried out to improve the sensitivities.

\section{Acknowledgement}

One of the authors (SSB) thanks the Council of Scientific and Industrial Research-Central Electrochemical Research Institute, Karaikudi for offering Research Internship and instrumental support to carry out this work.

\section{References}

1. Park H K, Han Y S, Do K K and Kim C H 1998 J. Mater. Sci. Lett. 17785

2. Hartley A, Sahibzada M, Westo M and Metcalfe I S 2000 Catal. Today 55197

3. Magraso A, Frontera C, Gunnaes A E, Tarancon A, Marrero-Lopez D, TrulsNorby and Haugsrud R $2011 \mathrm{~J}$. Power Sour. 1969141

4. Fino D, Russo N, Saracco G and Specchia V 2007 Prog. Solid State Ch. $\mathbf{3 5} 501$

5. Shimizu Y, Komatsu H, Michishita S, Miura N and Yamazo N 1996 Sens. Actuators B 34493

6. Panneerselvam M and Rao K J 2003 J. Mater. Chem. 13 596

7. Chick L A, Paderson L R, Maupin G D, Bates J L, Thomas L E and Exarhos G J 1990 Mater. Lett. 106

8. Chandradass J, Balasubramanian M and Kim K H 2010 Mater. Manuf. Process. 251449
9. Venkatesan M, Fitzgerald C B, Varadaraju U V and Coey J M D 2002 IEEE T. Magn. 52901

10. Manoharan S S and Patil K C 1992 J. Am. Ceram. Soc. 751012

11. Prabhakharan K, Joseph J, Gokhale N M, Sharma S C and Lal R 2005 Ceram. Int. 31327

12. Zupan K, Pejovnik S and Macek J 2001 Acta Chim. Slov. 48137

13. Mihai O, De C and Holmen A 2011 Ind. Eng. Chem. Res. $\mathbf{5 0} 2613$

14. Vernoux P, Djurado E and Guillodo M $2001 \mathrm{~J}$. Am. Ceram. Soc. 842289

15. Lan A and Mukasyan A S 2007 J. Phys. Chem. 1119573

16. Balasubramanian A, Karthikeyan N and Giridhar V V 2008 J. Power Sour. 185670

17. Atwan M H, Macdonald C L B, Northwood D O and Gyenge E 2006 J. Power Sour. 15836

18. Gyenge E, Atwan M H and Northwood D O $2006 \mathrm{~J}$. Electrochem. Soc. 153 A 150

19. Chatnet M, Micoud F, Roche I and Chainet E 2006 Electrochim. Acta $\mathbf{5 1 5 4 5 9}$

20. Wang L, Ma C, Mao X, Sheng J, Bai F and Tang F 2005 Electrochem. Commun. 71477

21. Wang L, Ma C and Mao X 2005 J. Alloys Compd. 397 313

22. Silva A L A, da Conceição L, Rocco A M and Souza M V M 2012 Ceramica $\mathbf{5 8} 521$

23. Wang H, Zhu Y, Liu P and Yaq W 2003 J. Mater. Sci. 381939

24. Devi P S and Rao M S 1992 J. Solid State Chem. 98237

25. Molina Concha B and Chatenet M 2009 Electrochim. Acta 546119 